\title{
BMJ Open Assessing healthcare expenditures of older United States adults with pain and poor versus good mental health status: a cross-sectional study
}

David Rhys Axon (D), Jonathan Chien

To cite: Axon DR, Chien J. Assessing healthcare expenditures of older United States adults with pain and poor versus good mental health status: a crosssectional study. BMJ Open 2022;12:e049727. doi:10.1136/ bmjopen-2021-049727

- Prepublication history for this paper is available online. To view these files, please visit the journal online (http://dx.doi. org/10.1136/bmjopen-2021049727).

Received 02 February 2021 Accepted 09 December 2021

Check for updates

(c) Author(s) (or their employer(s)) 2022. Re-use permitted under CC BY-NC. No commercial re-use. See rights and permissions. Published by BMJ.

Department of Pharmacy Practice \& Science, The University of Arizona College of Pharmacy, Tucson, Arizona, USA

Correspondence to

Dr David Rhys Axon;

axon@pharmacy.arizona.edu

\section{ABSTRACT}

Objectives This study aimed to determine if differences exist in healthcare expenditures of older United States (US) adults with pain based on self-reported mental health status, which is important to know given the prevalence of pain and poor mental health in the USA.

Design This was a cross-sectional study.

Setting US Medical Expenditure Panel Survey (MEPS) interviews.

Participants US adults aged $\geq 50$ years, with selfreported pain in the past 4 weeks and positive healthcare expenditure in the 2018 Medical Expenditure Panel Survey (MEPS). The independent variable was poor versus good mental health status.

Primary and secondary outcome measures Descriptive statistics compared demographic characteristics (using chi-square tests) and mean healthcare expenditures (using t-tests) between groups. Adjusted linear regression models with logarithmically-transformed expenditures compared differences in: total; inpatient; outpatient; emergency room; office-based; prescription medications and other expenditures. Analyses accounted for the complex MEPS design and were weighted to produce nationallyrepresentative results. The a priori alpha level was 0.05 . Results The weighted population included 57134711 older US adults with self-reported pain (14.4\% poor mental health, $85.6 \%$ good mental health). Compared with individuals with good mental health, individuals with poor mental health had higher unadjusted total expenditures (US\$20 231 vs US\$13 379, $p<0.0001$ ), higher prescription medication expenditures (US\$5924 vs US $\$ 3610$, $\mathrm{p}<0.0001$ ) and higher other expenditures (US\$4833 vs US $\$ 2285, p<0.0001)$. In adjusted multivariable linear regression models, there were no differences in expenditures between those with poor mental health and those with good mental health status.

Conclusions There were no statistically significant differences in adjusted annual (2018) positive healthcare expenditures among older US adults with pain and poor versus good mental health status.

\section{INTRODUCTION}

Pain and poor mental health are highly prevalent, detrimental conditions that have a considerable burden on the healthcare system, economy and quality of life. The

\section{Strengths and limitations of this study}

- Strengths of the study include a large nationally representative sample of older United States (US) adults, which produced findings generalisable to the non-institutionalised US population.

- Another study strength was the ability to produce weighted estimates that represented 57 million older US adults.

- Limitations of the study include the inability to draw a cause-and-effect relationship due to the crosssectional study design.

- Another study limitation was the use of self-reported data that may have been subject to recall bias, although this was minimised by the panel design of regular interviews.

- A further study limitation was that there are various definitions for pain, thus the definition of pain used in this study may produce different results from studies that used other definitions.

prevalence of pain among United States (US) adults ranges from 100 million to 126 million. Pain is also among the most frequently reported reasons for seeking medical care and can be burdensome to manage ${ }^{1-4}$ Prior research has found approximately two-thirds of adults experience lower back pain at some time. ${ }^{5}$ Other studies have found pain is significantly associated with older age (adults aged $\geq 50$ years old (adjusted OR2.03, 95\% CI 1.48 to 2.78$)$ ), with a reported prevalence as high as $55 \% .^{5-7}$ With a growing population of older US adults, pain management exerts significant annual economic costs estimated at US $\$ 560$ to US $\$ 635$ billion (in 2010 US $\$$ ). ${ }^{18}$ Prior research has found $20 \%$ of Americans experience poor mental health in a given year and $50 \%$ are diagnosed with mental illness during their lifetime. ${ }^{9}{ }^{10}$ Poor mental health status as a result of depression and anxiety exerts a global economic cost of US $\$ 1$ trillion (in 2013 US\$) per year due to lost productivity. ${ }^{11}$ 
Prior research has found, with a high prevalence of co-occurrence, a bidirectional relationship between pain (regardless of aetiology) and poor mental health. ${ }^{12}{ }^{13}$ The pathophysiological association between the physical and psychological symptoms is thought to be due to interrelated neural pathways. ${ }^{12}{ }^{14}$ A study by WHO found patients with self-reported pain had approximately three times the odds of reporting anxiety or depressive disorders. ${ }^{15}$ Previous research findings have also identified that the prevalence of depressive or mood disorders can exceed $50 \%$ in patients with pain such as fibromyalgia. ${ }^{12} 1617$ Meanwhile, other studies have found patients with depression were more likely to report pain and other physical problems compared with those with no mental health disorders. ${ }^{18} 19$

There are many pharmacological and nonpharmacological approaches that can be used to manage or treat pain and mental health disorders, including antidepressant medications (eg, serotonin-norepinephrine reuptake inhibitors, tricyclic antidepressants), ${ }^{20}$ psychological strategies (eg, cognitive behavioural therapy, counselling, therapy) ${ }^{21-23}$ and physical strategies (eg, exercise, massages) ${ }^{24}{ }^{25}$ However, despite the variety of pharmacological and non-pharmacological management strategies, pain and poor mental health remain highly prevalent in the USA. ${ }^{26}$

Prior research has explored the relationship between healthcare expenditures and pain $^{27}$ and the relationship between healthcare expenditures in specific populations of older adults with pain, including those with multiple chronic conditions and those with common comorbid conditions such as hypertension and hypercholesterolemia. ${ }^{28}$ Another recent study has explored the relationship between healthcare expenditures and general health status among older adults with pain. ${ }^{30}$ However, little is known about the healthcare expenditures among an older US adult population with self-reported pain and poor mental health status. Therefore, this study sought to identify if differences exist in healthcare expenditures between those with poor mental health and those with good mental health among a nationally representative sample of adults aged $\geq 50$ years with pain in the USA.

\section{METHODS}

\section{Study data and design}

Conducted on behalf of the Agency for Healthcare Research and Quality, the Medical Expenditure Panel Survey (MEPS) collects data in five interview rounds over a 2-year period and uses the sampling framework from the previous years' National Health Interview Survey. Survey participants provide oral informed consent before data are collected. One of the main MEPS components is the MEPS household component (MEPS-HC). MEPS-HC collates self-reported data on personal demographic characteristics, health conditions and health status and healthcare expenditures (among other things) for each household member surveyed. MEPS staff supplement
MEPS-HC data with data collected from the MEPS medical provider component (MEPS-MPC). MEPS-MPC healthcare expenditure data are typically more precise than MEPS-HC healthcare expenditure data; this process therefore improves the quality of healthcare expenditure data. MEPS healthcare expenditure data include the sum of annual payments for healthcare services made directly, out-of-pocket, by private insurance, by Medicaid, by Medicare and by other sources, but exclude payments for indirect payments not related to specific medical events and over-the-counter drugs. This cross-sectional study used the publicly-available 2018 full-year consolidated data file. These were the most recent data available at the time of the study and included data from interview rounds 3, 4 and 5 of survey panel 22 and interview rounds 1, 2 and 3 of survey panel $23 .{ }^{31} 32$

\section{Eligibility}

Subjects in the MEPS 2018 full-year consolidated data file were eligible for inclusion in this study if they were alive for the full calendar year, at least 50 years of age and had pain in the last 4 weeks. Pain was defined using responses to the pain question available in MEPS that asked: 'During the past 4 weeks, pain interfered with normal work outside the home and housework'. Respondents who indicated: 'a little bit', 'moderately', 'quite a bit' or'extremely' were included, while those who indicated 'not at all' were excluded. ${ }^{33} 34$ The analyses also only included subjects with positive healthcare expenditures (ie, those who used the healthcare system).

\section{Dependent variable}

The primary dependent variable in this study was total annual positive healthcare expenditures for eligible subjects in 2018. Secondary outcomes included the following specific categories of healthcare expenditures: inpatient expenditures; outpatient expenditures; emergency room expenditures; office-based expenditures; prescription medication expenditures and other expenditures. Inpatient expenditures were inclusive of all hospital inpatient visits. Inpatient, emergency room and outpatient expenditures were inclusive of all facility expenses and payments made to physicians for services provided but billed separately. Outpatient and officebased expenditures included visits to physicians and non-physician providers. Prescription medication expenditures included those associated with initial and refill out-of-pocket and third-party expenses. Home health expenditures included care provided by self-employed people as well as home health agencies, hospitals and nursing homes. Other healthcare expenditures included equipment and services such as glasses and contact lenses, vision aids, dental expenditures, ambulances, disposable supplies, other long-term equipment, home health expenditures for care provided by self-employed people as well as home health agencies, hospitals and nursing homes. ${ }^{334}$ 


\section{Independent variable}

The independent variable in this study was perceived mental health status. This was defined using responses to a question that asked survey participants to rate their mental health as 'poor', 'fair', 'good', 'very good' or 'excellent'. Respondents who indicated: 'poor' or 'fair' were deemed to have poor mental health, while those who indicated 'good', 'very good' or 'excellent' were deemed to have good mental health. ${ }^{33} 34$

\section{Control variables}

Potential confounding variables that were controlled for in adjusted analyses included: age (50-64, $\geq 65$ years); gender (male, female); race (white, other); ethnicity (Hispanic, non-Hispanic); marital status (married, other); education completed (up to high school, higher than high school); employment status (employed, unemployed); income (poor/near poor/low income, middle/high income); health insurance (private, public, uninsured), pain severity (quite a bit/extreme, little/moderate); limitation (yes, no); number of chronic conditions from the following list: angina, arthritis, asthma, cancer, chronic bronchitis, coronary heart disease, diabetes, emphysema, hypercholesterolemia, hypertension, joint pain, myocardial infarction, other unspecified heart disease, stroke ( $\geq 5,0-4)$; perceived health status (excellent/very good/ good, fair/poor); smoking status (smoker, non-smoker); frequent exercise status (yes, no) and census region (Northeast, Midwest, South, West). ${ }^{33} 34$

\section{Data analysis}

The demographic and descriptive characteristics of the two groups (poor and good mental health status) were compared using chi-square tests, while the mean annual healthcare expenditures of the two groups were compared using t-tests. Adjusted linear regression models were constructed to assess differences in healthcare expenditures between the poor mental health group and good mental health group. The assumptions of linear regression (no multicollinearity, homoscedasticity, independent observations, normality and linearity) were assessed. Due to the non-linear nature of the healthcare expenditure data, the data were logarithmically-transformed for analysis. Semilogarithmic equations were then used to calculate the per cent difference in healthcare expenditures between the two groups. ${ }^{35}$ Analyses were conducted using PROC SURVEY commands in SAS University (SAS Institute, Cary, NC, USA). Analyses were weighted appropriately to obtain nationally-representative estimates and to account for the MEPS complex survey design. Variance estimates were calculated using the Taylor-series linearisation method. Given the large sample size, a conservative alpha level of 0.001 was used to determine statistical significance. This report was prepared in accordance with the Strengthening the Reporting of Observational Studies in Epidemiology (STROBE) checklist. ${ }^{36}$
Patient and public involvement

No patients involved.

\section{RESULTS}

This study sample included 5123 eligible individuals, which represented a weighted population of 57134711 older US adults with pain in the past 4 weeks. Of these, $14.4 \%$ (95\% CI $13.3 \%$ to $15.4 \%$ ) perceived their mental health as poor and $85.6 \%$ (95\% CI $84.6 \%$ to $86.7 \%)$ perceived their mental health as good.

The majority of individuals in the study had the following characteristics: aged $\geq 65$ years $(51.6 \%)$, female $(55.7 \%)$, white race $(80.9 \%)$, non-Hispanic $(90.6 \%)$, married $(56.7 \%)$, higher than high school education completed $(55.0 \%)$, unemployed $(60.2 \%)$, middle/high income $(69.0 \%)$, private health insurance $(57.6 \%)$, little/ moderate pain severity $(74.6 \%)$, limitations $(50.8 \%), 0-4$ chronic conditions (75.8\%), excellent/very good/good perceived physical health status $(73.4 \%)$, non-smokers $(84.0 \%)$, no frequent exercise $(58.0 \%)$. The most common census region was the South $(38.4 \%)$. There were significant differences between individuals who reported poor mental health and those who reported good mental health for all characteristics $(\mathrm{p}<0.05)$ except age $(p=0.7658)$, gender $(p=0.4035)$, race $(p=0.9024)$ and region $(\mathrm{p}=0.2997)$ (table 1$)$.

Individuals with poor mental health status had higher descriptive (unadjusted) total healthcare expenditures compared with those with good mental health status (US\$20 231 vs US\$13 379, p<0.0001). Prescription medication and other expenditures were also higher in the poor mental health group versus the good mental health group (US\$5924 vs US $\$ 3610, \mathrm{p}<0.0001$ and US $\$ 4833$ vs US $\$ 2285, \mathrm{p}<0.0001$, respectively). There were no statistical differences between groups for the remaining healthcare expenditure categories (table 2).

In adjusted multivariable linear regression models, there were no significant differences in healthcare expenditures between those with poor mental health and those with good mental health status for any category of healthcare expenditures (table 3 ).

\section{DISCUSSION}

The key finding from this cross-sectional study was that there were no statistically significant differences in the 2018 healthcare expenditures of older US adults with selfreported pain between individuals with poor perceived mental health and those with good perceived mental health, after adjusting for potential confounding variables. Prior research using MEPS data found that healthcare expenditures were $105 \%$ higher among older US adults (aged $\geq 50$ years old) with pain who were prescribed opioids compared with those who were not. ${ }^{37}$ Another MEPS study found healthcare expenditures were $55 \%$ lower among older US adults (aged $\geq 50$ years old) with pain with excellent health status versus those with poor 
Table 1 Demographic and descriptive characteristics of older United States adults (aged $\geq 50$ years) with self-reported pain in the past 4 weeks, stratified by poor mental health and good mental health

\begin{tabular}{|c|c|c|c|c|c|c|c|}
\hline \multirow[b]{3}{*}{ Variables } & \multirow{2}{*}{\multicolumn{2}{|c|}{$\begin{array}{l}\text { Total } \\
\text { (Unweighted } n=5123 ; \\
\text { Weighted } n=57 \text { 134 711) }\end{array}$}} & \multirow{2}{*}{\multicolumn{2}{|c|}{$\begin{array}{l}\text { Poor mental health } \\
\text { (Unweighted n=822; } \\
\text { Weighted } n=8216 \text { 719) }\end{array}$}} & \multirow{2}{*}{\multicolumn{2}{|c|}{$\begin{array}{l}\text { Good mental health } \\
\text { (Unweighted } n=4301 ; \\
\text { Weighted } n=48917 \text { 992) }\end{array}$}} & \multirow[b]{3}{*}{ p } \\
\hline & & & & & & & \\
\hline & Weighted \% & $95 \% \mathrm{Cl}$ & Weighted \% & $95 \% \mathrm{Cl}$ & Weighted \% & $95 \% \mathrm{Cl}$ & \\
\hline \multicolumn{7}{|l|}{ Age (years) } & 0.7658 \\
\hline $50-64$ & 48.4 & 46.5 to 50.4 & 47.9 & 44 to 51.8 & 48.5 & 46.5 to 50.6 & \\
\hline$\geq 65$ & 51.6 & 49.6 to 53.5 & 52.1 & 48.2 to 56 & 51.5 & 49.4 to 53.5 & \\
\hline \multicolumn{7}{|l|}{ Gender } & 0.4035 \\
\hline Male & 44.3 & 43 to 45.7 & 42.7 & 38.5 to 46.8 & 44.6 & 43.1 to 46.1 & \\
\hline Female & 55.7 & 54.3 to 57 & 57.3 & 53.2 to 61.5 & 55.4 & 53.9 to 56.9 & \\
\hline \multicolumn{7}{|l|}{ Race } & 0.9024 \\
\hline White & 80.9 & 79.2 to 82.7 & 80.8 & 77.5 to 84 & 81 & 79.2 to 82.7 & \\
\hline Other & 19.1 & 17.3 to 20.8 & 19.2 & 16 to 22.5 & 19 & 17.3 to 20.8 & \\
\hline \multicolumn{7}{|l|}{ Ethnicity } & $<0.0001$ \\
\hline Hispanic & 9.4 & 7.7 to 11.2 & 16 & 11.7 to 20.3 & 8.3 & 6.9 to 9.8 & \\
\hline Non-Hispanic & 90.6 & 88.8 to 92.3 & 84 & 79.7 to 88.3 & 91.7 & 90.2 to 93.1 & \\
\hline \multicolumn{7}{|l|}{ Marital status } & $<0.0001$ \\
\hline Married & 56.7 & 54.8 to 58.6 & 45.7 & 41 to 50.4 & 58.5 & 56.6 to 60.5 & \\
\hline Other & 43.3 & 41.4 to 45.2 & 54.3 & 49.6 to 59 & 41.5 & 39.5 to 43.4 & \\
\hline \multicolumn{7}{|l|}{ Education completed } & $<0.0001$ \\
\hline Up to high school & 45 & 42.8 to 47.2 & 60.8 & 56 to 65.5 & 42.3 & 40.2 to 44.5 & \\
\hline $\begin{array}{l}\text { Higher than high } \\
\text { school }\end{array}$ & 55 & 52.8 to 57.2 & 39.2 & 34.5 to 44 & 57.7 & 55.5 to 59.8 & \\
\hline \multicolumn{7}{|l|}{ Employment status } & $<0.0001$ \\
\hline Employed & 39.8 & 37.3 to 42.4 & 17 & 13.7 to 20.4 & 43.6 & 40.8 to 46.4 & \\
\hline Unemployed & 60.2 & 57.6 to 62.7 & 83 & 79.6 to 86.3 & 56.4 & 53.6 to 59.2 & \\
\hline \multicolumn{7}{|l|}{ Income } & $<0.0001$ \\
\hline $\begin{array}{l}\text { Poor/near poor/low } \\
\text { income }\end{array}$ & 31 & 28.9 to 33 & 51.4 & 46.8 to 56.1 & 27.5 & 25.4 to 29.6 & \\
\hline Middle/high income & 69 & 67 to 71.1 & 48.6 & 43.9 to 53.2 & 72.5 & 70.4 to 74.6 & \\
\hline \multicolumn{7}{|l|}{ Health insurance } & $<0.0001$ \\
\hline Private & 57.6 & 55.3 to 59.8 & 36.8 & 32.1 to 41.5 & 61.1 & 58.7 to 63.5 & \\
\hline Public & 39.4 & 37.2 to 41.6 & 60 & 55.5 to 64.5 & 35.9 & 33.6 to 38.3 & \\
\hline Uninsured & 3 & 2.4 to 3.7 & 3.2 & 1.4 to 5 & 3 & 2.4 to 3.6 & \\
\hline \multicolumn{7}{|l|}{ Pain severity } & $<0.0001$ \\
\hline Quite a bit/extreme & 25.3 & 23.8 to 26.9 & 48.7 & 44.3 to 53 & 21.4 & 19.8 to 23 & \\
\hline Little/moderate & 74.7 & 73.1 to 76.2 & 51.3 & 47 to 55.7 & 78.6 & 77 to 80.2 & \\
\hline \multicolumn{7}{|l|}{ Limitation } & $<0.0001$ \\
\hline Yes & 50.8 & 48.7 to 53 & 79.7 & 76.3 to 83.1 & 46 & 43.7 to 48.2 & \\
\hline No & 49.2 & 47 to 51.3 & 20.3 & 16.9 to 23.7 & 54 & 51.8 to 56.3 & \\
\hline \multicolumn{7}{|c|}{ Number of chronic conditions } & $<0.0001$ \\
\hline$\geq 5$ & 24.2 & 22.5 to 25.9 & 36.3 & 32.3 to 40.2 & 22.2 & 20.4 to 23.9 & \\
\hline $0-4$ & 75.8 & 74.1 to 77.5 & 63.7 & 59.8 to 67.67 & 77.8 & 76.1 to 79.6 & \\
\hline \multicolumn{3}{|l|}{ Perceived health status } & & & & & $<0.0001$ \\
\hline $\begin{array}{l}\text { Excellent/very good/ } \\
\text { good }\end{array}$ & 73.4 & 71.7 to 75.1 & 26.1 & 22.3 to 29.9 & 81.3 & 79.7 to 82.9 & \\
\hline
\end{tabular}


Table 1 Continued

\begin{tabular}{|c|c|c|c|c|c|c|c|}
\hline \multirow{2}{*}{ Variables } & \multicolumn{2}{|l|}{ Total } & \multirow{2}{*}{\multicolumn{2}{|c|}{$\begin{array}{l}\text { Poor mental health } \\
\text { (Unweighted } n=822 ; \\
\text { Weighted } n=8216719 \text { ) }\end{array}$}} & \multirow{2}{*}{\multicolumn{2}{|c|}{$\begin{array}{l}\text { Good mental health } \\
\text { (Unweighted } n=4301 ; \\
\text { Weighted } n=48917992)\end{array}$}} & \multirow{2}{*}{$\mathbf{p}$} \\
\hline & \multicolumn{2}{|c|}{$\begin{array}{l}\text { (Unweighted } n=5123 ; \\
\text { Weighted } n=57134711 \text { ) }\end{array}$} & & & & & \\
\hline Fair/poor & 26.6 & 24.9 to 28.3 & 73.9 & 70.1 to 77.7 & 18.7 & 17.1 to 20.3 & \\
\hline Smoking status & & & & & & & $<0.0001$ \\
\hline Frequent exercise status & & & & & & & $<0.0001$ \\
\hline Yes & 42 & 40 to 44.1 & 28.8 & 25.1 to 32.5 & 44.2 & 42.1 to 46.4 & \\
\hline No & 58 & 55.9 to 60 & 71.2 & 67.5 to 74.9 & 55.8 & 53.6 to 57.9 & \\
\hline Census region & & & & & & & 0.2997 \\
\hline West & 22.4 & 20.4 to 24.4 & 21.3 & 17.9 to 24.8 & 22.5 & 20.4 to 24.7 & \\
\hline
\end{tabular}

Differences between the poor and good mental health groups based on chi-square tests.

health. ${ }^{30}$ However, our study findings indicate this is not the case in a population of older US adults with both pain and poor mental health.

There are several possible explanations for the findings of our study, including poor healthcare-seeking behaviour resulting from the aggregated barriers of healthcare disparities such as healthcare literacy, stigma and cost; and the financial preferences of pharmacological therapy rather than the underutilised, non-pharmacological therapy. ${ }^{21}$ Forty-five per cent of the individuals in this study had a high school education or less, some of whom may therefore have low health literacy. Low health literacy has been associated with limited access to healthcare services, poor utilisation of preventative care services, increased risk of experiencing worse health outcomes and higher lifetime healthcare expenditures. ${ }^{38-42}$ Similarly, stigma associated with mental health contributes to a low perceived need for medical assistance. Much of the media's portrayal of mental illnesses has focused on extreme variants-as a result, the more common mild-moderate cases of mental illness may be overlooked and patients may not consider their condition serious enough to seek help. ${ }^{43}$ Prior research has found mental health stigma to be associated with negative outcomes such as reduced income, employment and budgetary-allocation. ${ }^{44}$

Table 2 Descriptive healthcare expenditures of older United States adults (aged $\geq 50$ years) with self-reported pain in the past 4 weeks, stratified by poor mental health and good mental health

\begin{tabular}{|c|c|c|c|c|c|}
\hline \multirow[b]{2}{*}{ Healthcare expenditures } & \multicolumn{2}{|c|}{$\begin{array}{l}\text { Poor mental health } \\
\text { (Unweighted } n=822 \text { ) }\end{array}$} & \multicolumn{2}{|c|}{$\begin{array}{l}\text { Good mental health } \\
\text { (Unweighted } n=4301 \text { ) }\end{array}$} & \multirow[b]{2}{*}{$\mathbf{p}$} \\
\hline & Mean (US\$) & SE & Mean (US\$) & SE & \\
\hline Inpatient & 22290 & 3312 & 21341 & 1467 & 0.7876 \\
\hline Outpatient & 4123 & 722 & 3489 & 225 & 0.3965 \\
\hline Prescription medications & 5924 & 532 & 3620 & 186 & $<0.0001$ \\
\hline Other & 4833 & 486 & 2285 & 107 & $<0.0001$ \\
\hline
\end{tabular}

Analyses based on 5123 (unweighted) older United States adults (aged $\geq 50$ years) alive during the calendar year 2018 with self-reported pain in the past 4 weeks, but only include those who had positive healthcare expenditures for each healthcare expenditure category.

Total $n=4965$; Inpatient $n=826$; Outpatient $n=1912$; Emergency room $n=1233$; Office-based $n=4718$; Prescription medications $n=4669$; Other $\mathrm{n}=3674$.

Differences between the poor and good mental health groups based on t-tests. 
Table 3 Adjusted intercepts and parameter estimates for poor mental health compared with good mental health in older United States adults (aged $\geq 50$ years) with self-reported pain in the past 4 weeks, using logged positive healthcare expenditures

\begin{tabular}{|c|c|c|c|}
\hline Healthcare expenditure & Beta & SE & Significance \\
\hline \multicolumn{4}{|l|}{ Total } \\
\hline Poor mental health & 0.03 & 0.07 & 0.7099 \\
\hline Good mental health & Reference & & \\
\hline \multicolumn{4}{|l|}{ Inpatient } \\
\hline Poor mental health & -0.09 & 0.16 & 0.5661 \\
\hline Good mental health & Reference & & \\
\hline \multicolumn{4}{|l|}{ Outpatient } \\
\hline Poor mental health & 0.05 & 0.11 & 0.6438 \\
\hline Good mental health & Reference & & \\
\hline \multicolumn{4}{|l|}{ Office-based } \\
\hline Poor mental health & -0.11 & 0.07 & 0.1292 \\
\hline Good mental health & Reference & & \\
\hline \multicolumn{4}{|l|}{ Emergency room } \\
\hline Poor mental health & 0.02 & 0.12 & 0.8891 \\
\hline Good mental health & Reference & & \\
\hline \multicolumn{4}{|l|}{ Prescription medications } \\
\hline Poor mental health & -0.10 & 0.09 & 0.2438 \\
\hline Good mental health & Reference & & \\
\hline \multicolumn{4}{|l|}{ Other } \\
\hline Poor mental health & 0.13 & 0.09 & 0.1493 \\
\hline Good mental health & Reference & & \\
\hline
\end{tabular}

Analyses based on 5123 (unweighted) older United States adults (aged $\geq 50$ years) alive during the calendar year 2018 with self-reported pain in the past 4 weeks, but only include those who had positive healthcare expenditures for each healthcare expenditure category. Total $n=4904$; Inpatient $n=817$; Outpatient $n=1895$; Emergency room $n=1220$; Office-based $n=4667$; Prescription medications $n=4613$; Other $\mathrm{n}=3636$.

Differences modelled between the poor mental health group (unweighted $n=822$ ) and good mental health group (unweighted $n=4301$, reference group).

Models adjusted for the following variables: age, gender, race, ethnicity, marital status, education completed, employment status, income, health insurance, pain severity, limitation, number of chronic conditions, perceived health status, smoking status, frequent exercise status and census region.

Financial costs have proven consequential to pursuing healthcare services regardless of income; however, the principal reasons may vary between socioeconomic groups. ${ }^{45}$ While the Affordable Care Act has done much to reduce healthcare costs for low-income patients, financial barriers-to-access (such as lack of transport, childcare and work schedule) put low-income patients at a higher risk for poor mental health and longer hospitalisation periods. ${ }^{45-49}$ This may be explained by previous research findings that patients with low-income, when compared with high-income patients, were more likely to hold negative attitudes towards mental health treatment and demonstrate poor adherence to therapy. ${ }^{50}$ An alternative explanation for the higher rates of poor mental health and longer hospitalisation periods in low-income population groups may be variance in the quality of the services available. ${ }^{50}$ Consequently, underdiagnosed or mismanaged diseases can make it difficult for individuals to maintain employment. ${ }^{49} 50$ While healthcare services are generously covered through public insurances (such as Medicare and Medicaid), for patients with private insurance, fear of paying higher 'premiums' or re-occurring 'co-pays' for treatment, can dissuade patients from obtaining preventative-care health services. ${ }^{51} 52$ This may be the case in our study where the majority $(57.6 \%)$ had private health insurance. Overall, these barriers prevent older adults in need of healthcare services from obtaining assistance and demonstrate the need for greater budgetary allocations to facilitate outreach projects and healthcare providers to serve low-income patients. ${ }^{45} \mathrm{We}$ suggest that new public education initiatives and strategies to overcome such barriers are needed to improve the recognition of mental illness, improve health literacy and reduce the stigma associated with mental health. ${ }^{42} 43$

The clinical decision-making process for mental health treatment can vary based on the patient's medical history 
and medication risk-related adverse events. ${ }^{21}$ The preference of healthcare insurers for pharmacological therapy over non-pharmacological therapy may also explain why there were no differences in expenditures between mental health status in our study. Pharmacological therapy plays an imperative role for appropriately indicated therapy. Research has found medication classes such as serotoninnorepinephrine reuptake inhibitors and tricyclic antidepressants to be efficacious in treating both pain and poor mental health. ${ }^{20}$ Research has also observed a transition from non-pharmacological therapy towards antidepressant monotherapy regimens. ${ }^{53}$ Insurance coverage for antidepressant therapy has increased, although prescription drugs can account for two-thirds of out-of-pocket spending for mental healthcare. ${ }^{45}{ }^{46}$ In contrast, limitations in insurance coverage or having to pay additional out-of-pocket spending (that may vary by insurance type, facility type, provider rates) for non-pharmacological, psychotherapy services may deter patients from seeking mental healthcare and be detrimental to optimal therapy outcomes. ${ }^{54-56}$ Non-pharmacological, psychotherapy strategies (eg, cognitive behavioural therapy, behavioural therapy, problem-solving therapy) present several advantages such as avoiding adverse effects, or treating patients with poor coping strategies, environmental stressors or lack of social support. ${ }^{21-23}$ However, the limitations of non-pharmacological therapy intrinsically lie in its cost for both healthcare providers and patients. Given the lack of regulation and standardisation for nonpharmacologicalservices, 'low' insurance reimbursement rates may disincentivise providing these services. ${ }^{57}$ Additionally, non-pharmacological therapies may present a delayed onset of action for efficacy and take several weeks before observing any clinical improvements. ${ }^{53}$ Despite its limitations, psychotherapy in combination with medications (compared with medication use alone) has demonstrated superiority in both treatment adherence and clinical response ${ }^{58}{ }^{59} \mathrm{It}$ is imperative that all patients have access to high quality care given the increasing number of older adults with concurrent pain and poor mental health. ${ }^{8}$

Limitations of this study include the inability to draw a cause-and-effect relationship due to the study design and those inherent to the use of self-reported data. While one concern is recall bias, to minimise its effects, MEPS interviews are conducted at regular 4-5 months intervals. This study used the only self-reported pain variable included in the MEPS dataset; however, several other definitions of pain exist. The findings from this study might have differed if an alternative definition of pain had been used. Furthermore, the severity and sequence of diseases status was unable to be discerned from MEPS data. In addition, some individuals with selfreported pain and poor mental health may not meet clinical criteria for intervention. Finally, the analyses only included those with positive healthcare expenditures, thus those who did not have evidence of using the healthcare system were excluded. Analyses involving alternative statistical approaches (eg, two-part models of generalised linear models) would be needed to include these excluded individuals. However, strengths of this study are the use of a large nationally representative sample to produce findings that are generalisable to the non-institutionalised population. Future longitudinal research is needed to identify any differences in healthcare expenditures between individuals with poor versus good mental health in the long term.

\section{CONCLUSION}

This is the first study to investigate healthcare expenditures in older US adults with concurrent poor perceived mental health and self-reported pain. This study found no significant differences in positive healthcare expenditures between poor and good perceived mental health status among older US adults with pain. Reasons to explain these findings are offered along with suggestions for future research, which will be important to help improve our understanding of perceived mental health status in the ever-increasing older adult population.

Contributors Conceptualisation, DRA and JC; methodology, DRA; software, DRA; validation, DRA and JC; formal analysis, DRA; investigation, DRA; resources, DRA; data curation, DRA; writing — original draft preparation, DRA and JC; writingreview and editing, DRA; visualisation, DRA and JC.; supervision, DRA; project administration, DRA; funding acquisition, DRA; guarantor.

Funding The authors have not declared a specific grant for this research from any funding agency in the public, commercial or not-for-profit sectors.

Competing interests DRA has received research funding from the American Association of Colleges of Pharmacy, Arizona Department of Health Services, Pharmacy Quality Alliance, Merck \& Co. and Tabula Rasa HealthCare Group outside of this study.

Patient and public involvement Patients and/or the public were not involved in the design, or conduct, or reporting, or dissemination plans of this research.

Patient consent for publication Not applicable.

Ethics approval This study involves human participants but The University of Arizona Institutional Review Board deemed human subjects review was not required for this study (Protocol 2006721124; 12 June 2020 exempted this study). Participants gave informed consent to participate in the study before taking part.

Provenance and peer review Not commissioned; externally peer reviewed.

Data availability statement Data are available in a public, open access repository. All data used in this study are publicly available from the MEPS website: https:// www.meps.ahrq.gov/mepsweb/data_stats/download_data_files_detail.jsp? cboPufNumber=HC-209.

Open access This is an open access article distributed in accordance with the Creative Commons Attribution Non Commercial (CC BY-NC 4.0) license, which permits others to distribute, remix, adapt, build upon this work non-commercially, and license their derivative works on different terms, provided the original work is properly cited, appropriate credit is given, any changes made indicated, and the use is non-commercial. See: http://creativecommons.org/licenses/by-nc/4.0/.

ORCID iD

David Rhys Axon http://orcid.org/0000-0002-9903-5996

\section{REFERENCES}

1 Institute of Medicine (US) Committee on Advancing Pain Research, Care, and Education. Relieving pain in America: a blueprint for transforming prevention, care, education, and research. Washington, DC: National Academies Press, 2011. 
2 Nahin RL. Estimates of pain prevalence and severity in adults: United States, 2012. J Pain 2015;16:769-80.

3 Tompkins DA, Hobelmann JG, Compton P. Providing chronic pain management in the "Fifth Vital Sign" Era: Historical and treatment perspectives on a modern-day medical dilemma. Drug Alcohol Depend 2017;173 Suppl 1:S11-21.

4 Axon DR, Bhattacharjee S, Warholak TL, et al. $\mathrm{Xm}^{2}$ Scores for Estimating Total Exposure to Multimodal Strategies Identified by Pharmacists for Managing Pain: Validity Testing and Clinical Relevance. Pain Res Manag 2018;2018:1-11.

5 Deyo RA, Weinstein JN. Low back pain. N Engl J Med 2001;344:363-70.

6 Jakobsson U. The epidemiology of chronic pain in a general population: results of a survey in southern Sweden. Scand $J$ Rheumatol 2010;39:421-9.

7 Shmagel A, Foley R, Ibrahim H. Epidemiology of chronic low back pain in US adults: data from the 2009-2010 National health and nutrition examination survey. Arthritis Care Res 2016;68:1688-94.

8 Mather M, Scommegna P, Kilduff L. Fact sheet: aging in the United States. Available: https://www.prb.org/resources/fact-sheet-aging-inthe-united-states/ [Accessed 07 Oct 2021]

9 Bose J, Hedden SL, Lipari RN. Key substance use and mental health indicators in the United States: results from the 2015 national survey on drug use and health. Available: https://www.samhsa.gov/data/ sites/default/files/NSDUH-FFR1-2015/NSDUH-FFR1-2015/NSDUHFFR1-2015.pdf [Accessed 07 Oct 2021].

10 Kessler RC, Angermeyer M, Anthony JC. Lifetime prevalence and age-of-onset distributions of mental disorders in the world Health organization's world mental health survey initiative. World Psychiatry 2007;6:168-76.

11 Chisholm D, Sweeny K, Sheehan P, et al. Scaling-up treatment of depression and anxiety: a global return on investment analysis. Lancet Psychiatry 2016:3:415-24.

12 Hooten WM. Chronic pain and mental health disorders: shared neural mechanisms, epidemiology, and treatment. Mayo Clin Proc 2016;91:955-70.

13 Katon W, Sullivan M, Walker E. Medical symptoms without identified pathology: relationship to psychiatric disorders, childhood and adult trauma, and personality traits. Ann Intern Med 2001;134:917-25.

14 Watson D, Pennebaker JW. Health complaints, stress, and distress: exploring the central role of negative affectivity. Psychol Rev 1989;96:234-54.

15 Gureje O, Simon GE, Von Korff M. A cross-national study of the course of persistent pain in primary care. Pain 2001;92:195-200.

16 Aguglia A, Salvi V, Maina G, et al. Fibromyalgia syndrome and depressive symptoms: comorbidity and clinical correlates. J Affect Disord 2011;128:262-6.

17 Thieme K, Turk DC, Flor H. Comorbid depression and anxiety in fibromyalgia syndrome: relationship to somatic and psychosocial variables. Psychosom Med 2004;66:837-44.

18 Currie SR, Wang J. More data on major depression as an antecedent risk factor for first onset of chronic back pain. Psychol Med 2005;35:1275-82.

19 Kroenke K, Spitzer RL, Williams JB, et al. Physical symptoms in primary care. predictors of psychiatric disorders and functional impairment. Arch Fam Med 1994;3:774-9.

20 Marks DM, Shah MJ, Patkar AA, et al. Serotonin-Norepinephrine reuptake inhibitors for pain control: premise and promise. Curr Neuropharmacol 2009;7:331-6.

21 Lökk J, Delbari A. Management of depression in elderly stroke patients. Neuropsychiatr Dis Treat 2010;6:539-49.

22 Scogin F, Welsh D, Hanson A, et al. Evidence-Based psychotherapies for depression in older adults. Clinical Psychology: Science and Practice 2005;12:222-37.

23 Gaete JM, Bogousslavsky J. Post-Stroke depression. Expert Rev Neurother 2008;8:75-92.

24 Axon DR, Patel MJ, Martin JR, et al. Use of multidomain management strategies by community dwelling adults with chronic pain: evidence from a systematic review. Scand J Pain 2019;19:9-23

25 Geneen LJ, Moore RA, Clarke C, et al. Physical activity and exercise for chronic pain in adults: an overview of Cochrane reviews. Cochrane Database Syst Rev 2017;1:CD011279.

26 Haigh EAP, Bogucki OE, Sigmon ST, et al. Depression among older adults: a 20-year update on five common myths and misconceptions. Am J Geriatr Psychiatry 2018;26:107-22.

27 Gaskin DJ, Richard P. The economic costs of pain in the United States. J Pain 2012;13:715-24.

28 Axon DR, Vaffis S, Marupuru S. Identifying predictive characteristics of opioid medication use among a nationally representative sample of United States older adults with pain and comorbid hypertension or hypercholesterolemia. Health Care 2020;8:341.
29 Marupuru S, Axon DR. Association of multimorbidity on healthcare expenditures among older United States adults with pain. $J$ Aging Health 2021;33:741-50.

30 Axon DR, Kamel A. Patterns of healthcare expenditures among older United States adults with pain and different perceived health status. Healthcare 2021;9:1327.

31 Agency for Healthcare Research and Quality. Medical expenditure panel survey background. Available: https://meps.ahrq.gov/ mepsweb/about_meps/survey_back.jsp [Accessed 07 Oct 2021].

32 [dataset] Agency for Healthcare Research and Quality. Data from: medical expenditure panel survey HC-209 2018 full year consolidated data file. Medical expenditure panel survey website, 2020. Available: https://meps.ahrq.gov/mepsweb/data_stats/ download data files.jsp

33 Agency for Healthcare Research and Quality. MEPS HC-209 2018 full year consolidated data Codebook. Available: https://meps.ahrq.gov/ data_stats/download_data/pufs/h209/h209cb.pdf [Accessed 07 Oct 2021].

34 Agency for Healthcare Research and Quality. MEPS HC-209 2018 full year consolidated data file. Available: https://meps.ahrq.gov/data stats/download_data/pufs/h209/h209doc.pdf [Accessed 07 Oct 2021].

35 Halvorsen R, Palmquist R. The interpretation of Dummy variables in semilogarithmic equations. American Economic Review 1980;70:474-5.

36 von Elm E, Altman DG, Egger M, et al. The strengthening the reporting of observational studies in epidemiology (STROBE) statement: guidelines for reporting observational studies. J Clin Epidemiol 2008;61:344-9.

37 Axon DR, Slack M, Barraza L, et al. Nationally representative health care expenditures of community-based older adults with pain in the United States prescribed opioids vs those not prescribed opioids. Pain Med 2021;22:282-91.

38 Jordan JE, Buchbinder R, Briggs AM, et al. The health literacy management scale (HeLMS): a measure of an individual's capacity to seek, understand and use health information within the healthcare setting. Patient Educ Couns 2013;91:228-35.

39 Berkman ND, Sheridan SL, Donahue KE, et al. Low health literacy and health outcomes: an updated systematic review. Ann Intern Med 2011;155:97-107.

40 Song L, Mishel M, Bensen JT, et al. How does health literacy affect quality of life among men with newly diagnosed clinically localized prostate cancer? findings from the North Carolina-Louisiana prostate cancer project (PCaP). Cancer 2012;118:3842-51.

41 Dewalt DA, Berkman ND, Sheridan S, et al. Literacy and health outcomes: a systematic review of the literature. J Gen Intern Med 2004;19:1228-39.

42 Rasu RS, Bawa WA, Suminski R, et al. Health literacy impact on national healthcare utilization and expenditure. Int $J$ Health Policy Manag 2015;4:747-55

43 Ngui EM, Khasakhala L, Ndetei D, et al. Mental disorders, health inequalities and ethics: a global perspective. Int Rev Psychiatry 2010;22:235-44.

44 Sharac J, McCrone P, Clement S, et al. The economic impact of mental health stigma and discrimination: a systematic review. Epidemiol Psichiatr Soc 2010;19:223-32.

45 Rowan K, McAlpine DD, Blewett LA. Access and cost barriers to mental health care, by insurance status, 1999-2010. Health Aff 2013;32:1723-30.

46 Zuvekas SH, Meyerhoefer CD. State variations in the out-of-pocket spending burden for outpatient mental health treatment. Health Aff 2009;28:713-22.

47 Santiago CD, Kaltman S, Miranda J. Poverty and mental health: how do low-income adults and children fare in psychotherapy? J Clin Psychol 2013;69:115-26.

48 Snell-Johns J, Mendez JL, Smith BH. Evidence-Based solutions for overcoming access barriers, decreasing attrition, and promoting change with underserved families. J Fam Psychol 2004:18:19-35.

49 Stensland M, Watson PR, Grazier KL. An examination of costs, charges, and payments for inpatient psychiatric treatment in community hospitals. Psychiatr Serv 2012;63:666-71.

50 Mojtabai R, Olfson M, Sampson NA, et al. Barriers to mental health treatment: results from the National comorbidity survey replication. Psychol Med 2011;41:1751-61.

51 Shen Y-C, Long SK. What's driving the downward trend in employersponsored health insurance? Health Serv Res 2006;41:2074-96.

52 Taber JM, Leyva B, Persoskie A. Why do people avoid medical care? A qualitative study using national data. J Gen Intern Med 2015;30:290-7.

53 Olfson M, Marcus SC. National trends in outpatient psychotherapy. Am J Psychiatry 2010;167:1456-63. 
54 Hodgkin D, Horgan CM, Garnick DW, et al. Management of access to branded psychotropic medications in private health plans. Clin Ther 2007:29:371-80.

55 Teich JL, Buck JA. Mental health benefits in employer-sponsored health plans, 1997-2003. J Behav Health Serv Res 2007;34:343-8.

56 Medicare.gov. Mental health care (outpatient). Available: https://www. medicare.gov/coverage/mental-health-care-outpatient [Accessed 07 Oct 2021].
57 Wilk JE, West JC, Rae DS, et al. Patterns of adult psychotherapy in psychiatric practice. Psychiatr Serv 2006;57:472-6.

58 Pampallona S, Bollini P, Tibaldi G, et al. Combined pharmacotherapy and psychological treatment for depression: a systematic review. Arch Gen Psychiatry 2004;61:714-9.

59 March J, Silva S, Petrycki S, et al. Fluoxetine, cognitive-behavioral therapy, and their combination for adolescents with depression: treatment for adolescents with depression study (TADS) randomized controlled trial. JAMA 2004;292:807-20. 